\title{
La globalización y la política macroeconómica acentúan la financiarización y la fragilidad de las economías: el caso de México *
}

\author{
Arturo Huerta González,**
}

\begin{abstract}
Resumen
Las políticas económicas predominantes han impulsado la financiarización de las economías latinoamericanas, lo cual ha actuado en detrimento de las condiciones endógenas de acumulación y las ha llevado a depender del comportamiento de las exportaciones y la entrada de capitales, por lo que se colocan en un contexto de alta vulnerabilidad. Cuando éstas variables actuaron en forma positiva, se alcanzaron condiciones de estabilidad y cierto crecimiento. Al dejar de actuar en forma positiva, se manifiestan desequilibrios en las finanzas públicas y el sector externo, que desestabilizan la paridad cambiaria, el mercado de capitales y frenan el crecimiento. Los gobiernos están reaccionando con políticas monetarias y fiscales restrictivas, que debilitan más a las economías. Las economías latinoamericanas y en especial la economía mexicana, que es el objeto de estudio, no presentan perspectivas de crecimiento hacia el mercado externo, dada la desaceleración del comercio internacional, y las eventuales políticas proteccionistas que instrumentará el nuevo gobierno en Estados Unidos. Tampoco hay perspectivas de crecimiento hacia adentro, debido a que la liberalización económica y los altos niveles de endeudamiento les impide la flexibilización de la política económica.
\end{abstract}

Palabras-claves: Financiarización; Liberalización comercial y financiera; Variables externas; Vulnerabilidad; Estancamiento.

\section{Resumo}

\section{A globalização e a política macroeconômica acentuam a financeirização e a fragilidade das economias: 0 caso do México}

As políticas econômicas dominantes têm promovido a financeirização das economias da América Latina, em detrimento das condições endógenas de acumulação, o que resultou na dependência destas economias do comportamento das exportações e da entrada de capitais, que é a razão pela qual elas se encontram em uma condição de alta vulnerabilidade. Quando essas variáveis se comportaram de forma positiva, as condições de estabilidade e um certo crescimento foram atingidos. Quando deixaram de agir positivamente, o desequilíbrio das finanças públicas e do setor externo se manifestaram, desestabilizando as taxas de câmbio e os mercados de capitais e diminuindo o crescimento. Os governos estão reagindo com políticas fiscais e monetárias restritivas, que enfraquecem ainda mais as economias. Os países latino-americanos, em particular o México, objeto deste estudo, não apresentam perspectivas de crescimento na direção ao mercado externo devido à desaceleração do comércio internacional e eventuais políticas protecionistas do novo governo dos Estados Unidos. Há também a falta de

* Artículo recibido el 18 de diciembre de 2016 y aprobado el 18 de septiembre de 2017. Este trabajo se inscribe en el Proyecto PAPIIT IN304215 titulado Estancamiento y Desigualdad: Procesos que se Retroalimentan (1990-2014) auspiciado por la Dirección General de Apoyo al Personal Académico de la UNAM.

${ }^{* *}$ Profesor del Posgrado de la Facultad de Economía de la Unam. Cidade do México, México, E-mail: ahuerta@unam.mx. 
perspectiva de crescimento interno, dado que a liberalização econômica e os altos níveis de endividamento os impedem de flexibilizar sua política econômica.

Palavras-chave: Financiamento, Liberalização comercial e financeira; Variáveis externas; Vulnerabilidade; Estagnação.

\section{Summary}

The predominant economic policies have promoted the financialization of Latin American economies, which has been to the detriment of the endogenous conditions of accumulation and has led the economy to depend on the behavior of exports and capital inflow, which is why they are placed in a context of high vulnerability. When these variables acted in a positive way, conditions of stability and certain growth were reached. By failing to act positively, imbalances in public finances and the external sector manifest themselves, destabilizing exchange rate parity, the capital market and slowing growth. Governments are reacting with restrictive monetary and fiscal policies, which further weaken economies. The Latin American economies and in particular the Mexican economy, which is the object of study, do not present prospects for growth towards the external market, given the slowdown in international trade, and the eventual protectionist policies that the new government will implement in the United States. There is also no prospect of inward growth, because economic liberalization and high levels of indebtedness prevent them from flexibilizing economic policy.

Keywords: Financing; Commercial and financial liberalization; External variables; Vulnerability; Stagnation.

JEL E63, F11, G1, O11, O16, O23.

\section{Introducción}

En la parte inicial del trabajo, se analiza como la libre movilidad de mercancías y capitales y la política macroeconómica de estabilidad que le acompaña, han impulsado la financiarización de las economías en América Latina. Éstas se abrieron al comercio exterior en la perspectiva de impulsar su crecimiento hacia el mercado externo sin contar con las condiciones productivas y competitivas para ser exitosas. Las políticas han actuado en detrimento de la esfera productiva y han incrementado la dependencia de las economías a la entrada de capitales y al comportamiento de las variables externas.

A pesar de la crisis financiera de 2008-2009 se continúa con la misma política económica que impulsa la financierización de las economías, y las conduce a que otra crisis se vuelva a manifestar. En la segunda parte del trabajo se estudia el impacto que han tenido sobre las economías latinoamericanas los cambios adversos del comportamiento de las variables externas -caída de los precios internacionales de las materias primas y de las exportaciones, alza de la tasa de interés en EUA-, lo cual está desestabilizando a las finanzas públicas, al sector externo y a sus mercados financieros y de divisas. Se evidencia que la estabilidad alcanzada descansaba en el comportamiento positivo de las variables externas y que no tienen condiciones internas para ello, ni para sortear los shocks externos. La liberalización económica, como las presiones sobre las variables macroeconómicas y la gran deuda, impiden instrumentar políticas contra-cíclicas frente a la caída de exportaciones. Se genera 
un contexto de incertidumbre que frena la inversión y desestabiliza las paridades cambiarias y al mercado de capitales y cuestiona las políticas económicas predominantes.

Después el trabajo se centra en el análisis de cómo las políticas de libre movilidad de mercancias y capitales han actuado más a favor de la financiarización de la economía mexicana, y han incrementado las presiones sobre las variables macroeconómicos y los niveles de endeudamiento, colocándola en un contexto de alta fragilidad frente a los embates externos.

Se concluye en que no se puede continuar con las politicas económicas causantes de los problemas de bajo crecimiento, desempleo, subempleo, bajos salarios, creciente desigualdad del ingreso, y que no dan margen para superar los problemas que se enfrentan, por lo que aumenta el cuestionamiento de las mismas. Mientras no se regule el sector externo y el sector financiero, no hay viabilidad de flexibilizar la política económica para retomar las condiciones de crecimiento económico y de empleo.

\section{La libre movilidad de mercancías y capitales y la política que le acompaña han impulsado la financiarización en la mayoría de las economías}

A consecuencia de la instrumentación de las políticas que dieron paso a la libre movilidad de mercancías y capitales desde fines de los años ochenta en unos países y en otros desde los años noventa en América Latina, han pasado a predominar políticas macroeconómicas llamadas de estabilización, que privilegian objetivos de baja inflación, estabilidad del tipo de cambio, disciplina fiscal, que han trastocado el funcionamiento de las economías de la región, en detrimento de las bases productivas del crecimiento, y han impulsado el proceso de financiarización en éstas. Por concepto de financiarización se sigue el concepto desarrollado por G. Epstein, que caracteriza el crecimiento de los mercados, agentes, e instituciones financieras en las operaciones de la economía (2001), como el de O. Orhangazi, que lo señala como un cambio en la economía donde destaca el aumento de los mercados financieros, y la maximización de ganancias de las empresas no financieras en los mercados financieros (2011), así como el de Stockhammer, quien también destaca de cómo lo financicero pasa a tener mayor peso que antes en la economía (2010).

\subsection{Las economías latinoamericanas, en su gran mayoría, más unas que otras, procedieron a la apertura económica para impulsar la estrategia de crecimiento hacia fuera, sin tener condiciones endógenas para ello}

Diversas economías dejaron de lado desde los años ochenta unas, y otras desde inicios de los años noventa, sus políticas proteccionistas para abrir sus mercados bajo el principio que ello incrementaría su productividad y su acceso a los 
mercados externos. Ello respondió a presiones de las empresas transnacionales para aprovechar ventajas de localización, como ventajas competitivas y comparativas de los países para trasladarse a ellos y reducir sus costos y ampliar sus mercados a nivel internacional. A ello se suman los problemas de acumulación de los sectores productivos internos que muchos países latinoamericanos enfrentan, lo que ha llevado a que los gobiernos acojan y estimulen el establecimiento de empresas transnacionales que comandan el proceso de exportaciones y traen procesos productivos intensivos en mano de obra para aprovechar el bajo costo de ésta en países como México y Centro América y más al Sur. Un documento de la Unctad señala que "el $80 \%$ del comercio internacional se produce a lo largo de las cadenas de suministro de las empresas transnacionales" (2013).

La apertura comercial, junto a las políticas macroeconómicas de estabilidad predominantes (las cuales contraen el mercado interno), han impulsado la estrategia de crecimiento hacia fuera. Tales políticas generaron fuertes presiones sobre la balanza de comercio exterior, debido a la falta de condiciones productivas y competitivas para encarar importaciones, como para crecer hacia fuera por si solas. La apertura comercial lleva a que las exportaciones manufactureras tengan alto componente importado, por lo que la dinámica exportadora no se traduce en desarrollo manufacturero, ni de las economías. Prosiguen las presiones sobre el déficit de comercio exterior, lo que aumenta la dependencia de entrada de capitales para el financiamiento de dicho déficit, aumentando a su vez los niveles de endeudamiento interno y externo.

Parte de la entrada de capitales está vinculada al desempeño de las exportaciones, lo que coloca a la economía en una situación de alta dependencia al comportamiento del comercio internacional, como de los flujos de capital. Muchas economías pasan a ser susceptibles a shocks externos, debido a que no tiene condiciones endógenas para encarar las adversidades externas, como está aconteciendo de nuevo.

\subsection{Las políticas predominantes configuran un círculo vicioso al llevar a las economías a depender de la entrada de divisas y de capitales}

La política económica se ha encaminado a crear condiciones de estabilidad y rentabilidad para asegurar flujos de capital, necesarios para viabilizar la inserción de las economías en el contexto de globalización. La libre movilidad de capitales y el sector financiero demandan condiciones de baja inflación y estabilidad del tipo de cambio para garantizar la valorización de dicho capital. Como la mayoría de las economías emergentes no tiene condiciones endógenas para asegurar la estabilidad cambiaria y la reducción de la inflación, se instrumentan políticas dirigidas a contraer las presiones de demanda sobre precios, como para promover la entrada de capitales para financiar el déficit de cuenta corriente y estabilizar el tipo de cambio deseado 
por el capital financiero. Se ha optado por la instrumentación de políticas que aseguren superávit de cuenta de capitales, en lugar de aplicar políticas de flexibilización monetaria, cambiaria y fiscal dirigidas a encarar los problemas de oferta detrás del déficit de comercio exterior, pues bajo su concepción teórica, tales políticas generarían presiones inflacionarias que comprometerían los objetivos de 'estabilidad' deseados por el sector financiero.

La cuestión financiera pasa a ser cada vez más importante, tanto por los requerimientos financieros internos y externos, por lo que han predominado políticas macroeconómicas de diferenciales de tasas de interés (internas vs externas), de disciplina fiscal y estabilidad cambiaria, las cuales se dirigen a asegurar las condiciones de estabilidad y confianza deseadas por el sector financiero, a costa de contraer el crecimiento del mercado interno, y atentar sobre las condiciones endógenas de acumulación, lo que aumenta el déficit de cuenta corriente, por lo que se pasa a depender del comportamiento de las exportaciones y de sus principales socios comerciales. Se cae en un círculo vicioso que coloca a las economías en un contexto de alta fragilidad y vulnerabilidad.

La autonomía del banco central le quita el control de la moneda a los gobiernos, y lo subordinan al objetivo de la estabilidad del poder de compra de la moneda, a costa de dejar de tener política económica a favor del crecimiento. Justifican dicha política con el objetivo de reducir la inflación, para así supuestamente evitar inestabilidad financiera, pero el verdadero propósito es obligar a los gobiernos a trabajar con disciplina fiscal para reducir su tamaño y participación en la economía y así ampliar la de la cúpula empresarial en ésta. La estabilidad financiera se logra, no reduciendo la inflación, sino generando condiciones de reembolso de los créditos otorgados, para lo cual el ingreso de los deudores debe crecer por arriba del costo de la deuda, lo que no logran las políticas macroeconómicas de 'estabilidad'.

Con la autonomía monetaria, los gobiernos no pueden financiarse emitiendo moneda, y tienen que adecuar sus gastos a su nivel de ingresos, o recurrir al endeudamiento si caen en déficit. Los gobiernos no pueden obligar al banco central a que instrumente una política monetaria acomodaticia que acompañe el gasto deficitario, ni a flexibilizar la política monetaria para impulsar la dinámica económica y el empleo, ni para monetizar la deuda pública, ante el temor de generar inflación y devaluación que puedan afectar al sector financiero.

La creación de dinero que realizan los bancos centrales, siempre está presente para valorizar los activos financieros en contextos de crisis y para rescatar a la banca y a los acreedores, pero no a los deudores, ni para impulsar el empleo y la esfera productiva. No encaran los problemas de insolvencia que la generó, por lo que la eventualidad de otra crisis sigue estando presente, debido a que la política 
predominante no logra compatibilizar la baja inflación con el crecimiento sostenido, y las condiciones de reembolso de la deuda, para evitar caer en sobreendeudamiento $\mathrm{y}$ en crisis.

Las políticas macroeconómicas de estabilidad han ido acompañadas de reformas estructurales de privatización y extranjerización de sectores estratégicos, para que fluya el capital, para que aumenten la demanda por activos y por moneda nacional. Se obtienen así divisas para encarar los desequilibrios productivos internos, así como del sector público y del sector externo, lo que permite fortalecer la estabilidad cambiaria. Ello ha reducido el tamaño y participación del estado en la economía y ha ampliado la esfera de influencia del gran capital nacional e internacional y acelerado el proceso de privatización de la economía, sin tener efectos favorables sobre la dinámica económica, ni en la disminución de las presiones sobre el sector externo.

Las políticas macroeconómicas van dirigidas a crear confianza y rentabilidad en los mercados de capitales y de dinero, lo que impulsa la participación de lo financiero y le amplían al gran capital los sectores rentables donde invertir.

Los precios internacionales de las materias primas exportadas, como las exportaciones, las remesas, la deuda externa y la inversión extranjera, han pasado a ser importantes, tanto por su incidencia en la demanda, como en el sector externo, y en las reservas internacionales, como en las condiciones de 'estabilidad' que exige el sector financiero. Ante la importancia que tiene la entrada de capitales, obliga a que se institucionalice la política económica a su favor y se releguen los objetivos de crecimiento ante el temor inflacionario que pueda desestimular la entrada de capitales.

\subsection{La financiarización de las economías y la creciente desigualdad del ingreso}

Las políticas macroeconómicas que han impulsado la financiarización de las economías, las han hecho más dependientes de los inversionistas y acreedores externos, lo que ha incrementado la desigualdad del ingreso. Tales problemas estructurales serán difíciles de revertir, dado el poder económico y político del sector financiero, que defiende dichos cambios, ya que se ha beneficiado de ellos, a cambio de aumento de desempleo, caída de salarios, presiones sobre el sector externo, bajo crecimiento económico y del ingreso per-capita de la población. En EUA de 2005 a 2014, el ingreso real se mantuvo o cayó en el 65-70\% de las familias (McKinsey, citado por Sundaram; Popov, 2016).

El mayor poder que adquiere el sector financiero, le permite dictar una política económica a su favor, y al generarse mejores condiciones de ganancias en lo financiero, en relación a lo productivo, lleva a que los recursos sigan canalizándose hacia lo financiero. Se incrementan los precios de los activos 
financieros, por lo que pasan a ser más atractivos, lo que distorsiona más la asignación de recursos. Muchas empresas cambian la composición de sus activos a favor de los activos financieros. Ello lleva a que la participación de las ganancias financieras en el total de ganancias aumente. De tal forma, la dinámica de acumulación de muchas empresas pasa a depender más del comportamiento de los mercados de capitales, que de la esfera productiva y del desempeño de la economía. Señala Orhangazi que "un cambio fundamental en la economía fue el aumento de los mercados financieros y la maximización de ganancias de las empresas no financieras en los mercados financieros (2011).

\subsection{La crisis de 2008-09 lleva a la flexibilidad de la política monetaria en los países desarrollados, lo que sigue impulsando la financiarización de las economías}

Los estragos de la crisis de 2008-09 no se han superado a pesar de la flexibilización de la política monetaria, reflejada en inyecciones de liquidez, como en bajas tasas de interés en los países desarrollados. Ello evidencia que los problemas que la ocasionaron siguen estando presentes y no se resuelven con esa política monetaria, la cual ha actuado a favor del sector financiero. En el caso de EUA, a pesar de la baja tasa de interés de corto plazo en EUA, primero entre 0 y $0.25 \%$ y después entre 0.25 y $0.5 \%$, la de largo plazo a 10 años está cerca de $2 \%$, y la tasa de interés a la que la banca presta es más alta que el crecimiento del ingreso nacional en dicho país, que ronda al $2 \%$ promedio anual en los últimos años, por lo que no estimula el crecimiento de la inversión, y menos con el dólar apreciado que reduce su competitividad.

La flexibilización de la política monetaria en EUA, se ha canalizado a reestructurar la deuda de largo plazo que presenta un rendimiento mayor, por una de corto plazo. La Reserva Federal compra deuda de largo plazo por deuda de corto plazo a menor tasa de interés y así se reducen las presiones sobre las finanzas públicas (Rogoff, 2016a).

Tal política monetaria fue acompañada del déficit fiscal en 2009 en Estados Unidos, lo que permitió salir de la crisis, pero a partir 2010 empieza a reducirse el déficit fiscal y se descansa solo en el aumento de liquidez y la reducción de la tasa de interés para impulsar el crecimiento. Al dejar de operar la flexibilidad de la política fiscal y no crecer la demanda, ha llevado a que la mayor liquidez se canalice a lo financiero, impulsando la financiarización de las economías de los países desarrollados y en desarrollo, lo que no impulsa la actividad productiva.

La flexibilización de la política monetaria en EUA ha generado efecto riqueza en los poseedores de los títulos, debido a que el alza de los precios de los activos financieros, beneficia a millones de participantes en el mercado de capitales 
en dicha economía y origina un efecto positivo sobre la demanda y la actividad económica. Ello contribuye a explicar el por qué dicha economía ha crecido en mejores términos que el resto de las economías desarrolladas, debido a que en ellas el crecimiento del precio de las acciones no se ha traducido en aumento de demanda, debido a que no son tantos los participantes en sus mercados de capitales. Sin embargo, la flexibilidad de la política monetaria no ha logrado configurar un crecimiento permanente de la economía de EUA y que ésta alcance los niveles que venía teniendo antes de la crisis de 2008-09, debido al creciente componente importado de su demanda. Además, la mayor demanda generada, solo se mantiene durante el boom del mercado de capitales, y deja de crecer al caer dicho mercado (Roach, 2016).

Se ha evidenciado qué por más flexibilidad de la política monetaria, no se retoma el crecimiento. Si bien ello baja el costo de la deuda, no se flexibiliza la política fiscal. Para aumentar la inversión, el empleo y la actividad económica, ante el temor inflacionario que podría trastocar los intereses del sector financiero.

\subsection{Dependencia y vulnerabilidad respecto al comportamiento de la política monetaria de EUA y de los mercados financieros internacionales}

Las economías emergentes se colocan en un contexto de alta vulnerabilidad, pues dependen altamente de la entrada de capitales y cualquier restricción de la liquidez y aumento de la tasa de interés internacional, o cambio de expectativas, provoca la salida de capitales de sus mercados, y el derrumbe de los precios de los activos financieros ahí cotizados. Son por lo tanto vulnerables al comportamiento de la política monetaria de EUA, como de los mercados financieros internacionales y del comercio internacional. La desaceleración de una gran economía, como la inestabilidad de los mercados financieros, afectan los flujos de capitales y de divisas hacia las economías emergentes, lo que impacta sobre las variables macroeconómicas, como sobre la estabilidad cambiaria y su dinámica económica. Las economías son vulnerables al comportamiento de los precios internacional de las materias primas que exportan, como del volumen de las exportaciones, de los flujos de capitales y de la disponibilidad de endeudamiento externo. Mayor es el impacto de estas variables cuando las economías han visto deterioradas sus condiciones productivas internas, cuando tienen altos niveles de endeudamiento y cuando han perdido el manejo soberano de su política económica, por lo que no pueden hacer frente a los shocks externos.

Las economías, asimismo, pasan a estar sujeta a la percepción que el capital financiero tenga sobre el desempeño de ellas. Es decir, de sus variables macroeconómicas, de sus niveles de endeudamiento, de su capacidad de crecimiento y de reembolso de la deuda. 


\section{Cambios adversos de las variables externas debilitan a las economías latinoamericanas y a la financiarización}

\subsection{Cambio de la política monetaria en EUA}

Al frenar la Reserva Federal su inyección de liquidez a los mercados financieros en 2014 y anunciar que aumentaría la tasa de interés en 2015 y normalizaría su política monetaria, provocó que empezaran a regresar los capitales a EUA, que antes habían salido, ante la flexibilización monetaria y el diferencial de tasas de interés que otras economías ofrecían.

Con la restricción de la liquidez y el alza de la tasa de interés en EUA, se quiere evitar que continúe el boom en los mercados de capitales que se ha venido dando por la flexibilidad monetaria. Dicha política no logrará dicho objetivo, sino al contrario, al seguir aumentando la tasa de interés en EUA, habrá movimientos en los mercados de capitales y de divisas a nivel mundial, pues continuarán los flujos de capitales hacia el mercado financiero de EUA. Ello apreciará más el dólar y reducirá la competitividad de los productos estadounidenses, afectando sus exportaciones, lo que incrementará el déficit de comercio exterior y podrá afectar la dinámica de acumulación de empresas productivas.

La libre movilidad de capitales obliga a las economías emergentes a tomar en cuenta el manejo de la política monetaria de EUA, pues es el mercado de dinero de referencia del capital financiero ubicado en éstos países. Al cambiar la Reserva Federal su política monetaria, se restringe el flujo de recursos hacia las economías emergentes, con lo cual han financiado sus desequilibrios macroeconómicos y estabilizado su paridad cambiaria. Es decir, se pasa a comprometer el financiamiento de la cuenta corriente de balanza de pagos, como del déficit fiscal, lo que aumenta la incertidumbre que propicia salida de capitales y reducción de las reservas internacionales, además de desestabilizar el mercado de capitales y de divisas.

Ante ello las economías emergentes reaccionan con aumento de la tasa interna de interés para mantener un diferencial de tasas de interés con Estados Unidos que pretende ser atractivo para que el capital no salga y continúe fluyendo a éstos mercados. El alza de la tasa de interés externa e interna, actúa en detrimento de la asignación de recursos hacia el sector productivo y acentúa los problemas financieros de los sectores altamente endeudados. Aumenta el costo de la deuda y la transferencia de recursos hacia los acreedores con la consecuente mayor descapitalización de los deudores, los que nunca terminarán de pagar su deuda por el menor crecimiento que se genera de sus ingresos en proporción al mayor crecimiento del costo y monto de la deuda.

Se incrementan las presiones sobre las finanzas públicas, del sector privado y el déficit de cuenta corriente de balanza de pagos, evidenciando la fragilidad de las economías ante el contexto internacional adverso, el cual ya las ha afectado por la 
menor cantidad de divisas recibidas por la caída del precio internacional de sus materias primas y del petróleo, como por las menores exportaciones.

Ante el clima de incertidumbre, de alta vulnerabilidad y problemas de crecimiento en países desarrollados, como en desarrollo, lo mejor para las economías, es que siga postergándose la 'normalidad' de la política monetaria en EUA, dado el impacto negativo que ello tendría para la economía de Estados Unidos y del resto del mundo. El economista Kenneth Rogoff señala que "varios bancos centrales, incluida la Reserva Federal, han considerado la posibilidad de pasar a una meta de inflación más alta" (2016b) con el fin de poder flexibilizar más la política monetaria y llevarla a niveles negativos para reactivar la economía, pero que ello no se hace porque comprometería la credibilidad de los bancos centrales. Vemos como se sigue sacrificando el objetivo de crecimiento económico, para no trastocar la valorización del capital financiero, que demanda baja inflación y estabilidad del poder de compra de la moneda. En la zona euro y en Japón no se ven perspectivas de que vayan a modificar su tasa de interés negativa o de cero, y hasta en China hay demandas a su banco central para que baje la tasa de interés para impulsar el crecimiento (Reinhart, 2016).

\subsection{El comportamiento negativo de las variables externas y su impacto en las economías en desarrollo y en los mercados de capitales y de divisas}

Cuando dejan de actuar positivamente las variables externas (precio internacional de las materias primas y el petróleo, las exportaciones y la entrada de capitales), se comprometen los equilibrios macroeconómicos (el fiscal y del sector externo), como la estabilidad cambiaria.

Las condiciones endógenas de acumulación son importantes para contrarrestar tal situación, como para mantener los flujos de capital y evitar la salida de éstos de la economía. El problema es que la mayoría de las economías no cuentan con ello, y enfrentan presiones sobre el sector externo y las finanzas públicas, así como altos niveles de endeudamiento interno y externo, por lo que aumenta la incertidumbre de pago. A ello se suma el cambio de la política monetaria en EUA que contribuye a reducir la entrada de capitales al país.

El clima de incertidumbre generado por la política de la Reserva Federal de alzas de la tasa de interés, junto al hecho que prosiguen los problemas económicos en Japón, como en Europa y la desaceleración económica de China, y del comercio mundial, actúan contra las expectativas de las economías latinoamericanas, como sobre el comportamiento de su mercado financiero y de sus variables macroeconómicas, que ahuyentan más los flujos de capital hacia estos mercados, y provocan la salida de los mismos. 
Al disminuir los flujos de capital al país por las menores opciones de rentabilidad, como por el riesgo de devaluación de la moneda y de su capital, aumenta la incertidumbre y el riesgo de no pago, por lo que lleva al capital a buscar opciones de rentabilidad mayores y seguras en otros mercados, por lo que sale y devalúa la moneda. Kaltenbrunner, citando a Kregel señala que el tipo de cambio, como relación entre la moneda interna y la moneda externa es una manifestación del diferencial de rendimiento interno versus externo (2015, p. 430).

Al responder los gobiernos con políticas contraccionistas frente a las presiones sobre las finanzas públicas y el sector externo para frenar la salida de capitales, se generan consecuencias negativas de largo alcance a la economía, dada la fuerte caída de la inversión, como la desaceleración de la actividad económica.

Al no haber entrada de capitales suficientes que financien el déficit externo, este pasa a ser insostenible, por lo que tiene que ajustarse a la entrada de capitales que reciba la economía. El problema es la magnitud que tendrían que alcanzar la devaluación de la moneda y las políticas monetarias y fiscales restrictivas, para realizar el ajuste externo necesario para adecuarlo a su financiamiento. El alza de la tasa de interés y el menor gasto público, atentan sobre las condiciones endógenas de acumulación, por lo que menos condiciones se tienen para ajustar el déficit de comercio exterior, por lo que prosiguen las presiones sobre las variables macroeconómicas, y el clima de incertidumbre y fragilidad de la economía. Además, ello impacta en el mercado de capitales, en los ingresos de empresas e individuos, en los problemas de insolvencia y en la 'estabilidad' del sector bancario. La devaluación de la moneda, desestabiliza el mercado de capitales, dada la desvalorización que origina a dicho capital, por lo que se acelera la salida de capitales, situación que lleva a la crisis. Ello llevará a replantear la libre movilidad de mercancías y capitales y las políticas económicas que le acompañan, lo que evidencia el ocaso del proceso de globalización predominante, a diferencia de aquellos que demandan más globalización para encarar los desequilibrios mundiales, como los economistas del Banco Mundial (Canuto, 2016), sin reconocer que ha sido la propia globalización la causante de la agudización de los mismos. Asimismo, Dervis señala que "los principales desafíos que enfrentamos hoy en día, son de naturaleza global" (Dervis, 2016). Se ha caído en tal situación, debido a la alta dependencia que tenemos del exterior, como consecuencia de las políticas económicas predominantes.

\subsection{Al reaccionar los gobiernos frente a los shocks externos con políticas pro- cíclicas para defender la financiarización, debilitan la economía}

Frente a la caída de exportaciones y el impacto negativo que tiene sobre la actividad económica, los gobiernos no pueden actuar en forma contra-cíclica, es decir, bajar la tasa de interés e incrementar el gasto público para promover el 
crecimiento del mercado interno, debido a que temen que aumente la inflación, el déficit fiscal y del sector externo y las presiones devaluatorias y las salidas de capitales. Se responde con alza de la tasa de interés y disminución del gasto público para mandar señales de que se generará ahorro forzoso y capacidad de pago de las obligaciones financieras existentes. Sin embargo, tales políticas contraen más la economía, por lo que menos capacidad pasa ésta a tener para encarar el entorno internacional adverso, por lo que no se genera el ahorro forzoso para cubrir el pago de la deuda.

La posición de los gobiernos de disminuir el gasto público para alcanzar superávit primario, para encarar el pago de la deuda, no consideran que las exportaciones están cayendo, y que el sector privado no está incrementando el consumo y la inversión. El menor gasto e inversión, tanto del sector público como privado, atenta sobre el crecimiento de la productividad y mantiene las presiones de oferta sobre el déficit de comercio exterior, por lo que prosiguen las presiones sobre tales variables macroeconómicas y sobre el tipo de cambio, lo que debilita al sector financiero, dado que dejan de existir las condiciones macroeconómicas de 'estabilidad' que requiere para operar.

\subsection{Problemas de insolvencia e inestabilidad bancaria}

Ante los problemas de pago de deuda que enfrentan empresas e individuos, no pueden recurrir a más deuda para encarar sus problemas financieros, por lo que tienen que realizar fuertes restricciones de inversión y consumo para hacer frente al pago de su deuda. Por más que los tomadores de decisiones señalen que la estabilidad cambiaria-monetaria es necesaria para la estabilidad financiera, ésta no se logra con las políticas macroeconómicas de estabilidad predominantes. La banca ante los problemas de insolvencia, recorta los créditos, que contrae más la actividad económica y la capacidad de pago de los deudores. Al acentuarse los problemas de insolvencia e inestabilidad, la banca demandará de apoyos gubernamentales, pero ahora se dará en un contexto donde los gobiernos enfrentan severas presiones sobre sus finanzas, dada la caída del precio internacional de las materias primas y del petróleo, como por los mayores niveles de endeudamiento en que ha caído y el incremento de su costo.

\section{México en el contexto de la globalización y la financiarización}

\subsection{Con la libre movilidad de capitales se deja de tener política económica a favor del crecimiento, para no afectar lo financiero}

En México, el banco central a diferencia de la Reserva Federal de Estados Unidos, no responde a los objetivos de crecimiento y de bajo desempleo. La pérdida de control de la moneda por parte del gobierno, aunado a la elusión y evasión 
tributaria y la baja recaudación tributaria, obliga al gobierno a contraer gasto e inversión en sectores claves de la economía y en bienestar social, para alcanzar la disciplina fiscal. Además, lo lleva a abrirle espacios rentables de inversión a la cúpula empresarial, la cual pasa a invertir donde el gobierno deja de hacerlo. La privatización de varios sectores estratégicos, se ha realizado a través del mercado de capitales, lo que acentúa más la financiarización de la economía. Al caer el gobierno en déficit y al no poder financiarse con su moneda, tiene que recurrir a los mercados de dinero para colocar deuda, por lo que ha visto incrementados sus niveles de endeudamiento, que terminan favoreciendo al sector financiero.

No se flexibiliza la política monetaria y fiscal (y por muchos años no se flexibilizó la política cambiaria) a favor del crecimiento y del empleo, ante el temor inflacionario y de mayores presiones sobre las variables macroeconómicas que pudieran desestabilizar al mercado de divisas y de capitales.

Por más que el banco central en México señala que se trabaja con tipo de cambio flexible desde la crisis de 1995, ha hecho todo lo posible para mantener la estabilidad cambiaria para favorecer al sector financiero, debido a que ello le garantiza la valorización de su capital. Ha predominado la apreciación cambiaria desde 1997 hasta mediados de 2014 (véase Gráfica 1, Huerta, 2017), lo que actúa en detrimento de la competitividad, de la producción nacional, y mantiene latentes las presiones sobre el déficit de comercio exterior. El banco central no ha optado por un tipo de cambio sea flexible en torno al diferencial de precios y productividad entre el país y su principal socio comercial para disminuir el déficit de comercio exterior, sino que trabajan con un tipo de cambio a favor de la entrada de capitales para asegurar superávit de cuenta de capitales para ajustar la balanza de pagos. La flexibilización y la consecuente devaluación, se presenta cuando disminuye la entrada de capitales, sea por la caída de exportaciones, como por la menor entrada de capitales, lo que refleja que la paridad cambiaria ha sido flexible al movimiento de capitales, y el gobierno hace todo lo posible para que la entrada de capitales sea mayor que la salida, para evitar devaluación. De ahí el diferencial de tasas de interés que mantiene frente a Estados Unidos, como la política de austeridad fiscal y las reformas estructurales.

El gobierno podría trabajar con gasto deficitario a favor de la inversión, para impulsar el desarrollo tecnológico, para incrementar productividad y capacidad la productiva, para reducir las presiones de oferta sobre el déficit de comercio exterior, sin que ello genere inflación, pero no optan por ello por la creencia de que todo gasto genera inflación y afecta al sector financiero. El trasfondo de la política de austeridad, es abrir espacios de inversión al sector privado para que no se vaya y vengan capitales para así financiar el déficit externo, como para impulsar la financiarización de las economías, dejando a estos agentes la conducción de la economía. 


\subsection{La política macroeconómica predominante ha llevado a que la entrada de capitales no favorezca la inversión productiva, sino la financiarización de la economía}

La política macroeconómica no solo garantiza la valorización del capital invertido en el sector financiero, sino que también le han ampliado sus ganancias, dados los mayores niveles de endeudamiento en que ha caído la economía. Ello ha llevado a que la asignación de recursos actúe a favor de lo financiero y en detrimento de lo productivo. Ante la contracción del mercado interno y externo y la pérdida de competitividad, muchas empresas buscan opciones de inversión fuera del sector productivo, por lo que invierten en el sector financiero, así como en los sectores estratégicos donde deja de invertir el gobierno. La mayor entrada de capitales dirigida al mercado de capitales y de dinero, ha impulsado la innovación financiera que amplía opciones de inversión atractivas en dicho sector, por lo que se acelera la financiarización. Señala Toporowski que "es el crecimiento de los flujos financieros que desplazaron la inflación desde el sector productivo hacia el sector financiero", lo que retroalimenta dicho proceso (2000).

La inversión extranjera directa que ha ingresado a México, más que aumentar la capacidad productiva y contribuir al crecimiento económico, ha sido para adquirir acciones de empresas que se cotizan en el mercado de capitales (véase Cuadro 1) para tener el control de ellas, así como adquirir directamente empresas y activos nacionales e invierten en sectores estratégicos, lo que representa un cambio patrimonial, sin representar ello aumento de la capacidad productiva.

Cuadro 1

México: PIB y flujos de inversión extranjera a la BMV, 2009-2015

\begin{tabular}{cccc}
\hline Años & $\begin{array}{c}\mathbf{( 1 )} \\
\text { PIB } \\
\text { (pesos corrientes) }\end{array}$ & $\begin{array}{c}\text { (2) } \\
\text { Flujos de inversión Extranjera a } \\
\text { la BMV }\end{array}$ & $\begin{array}{c}\mathbf{2 / 1} \\
\mathbf{\%}\end{array}$ \\
\hline 2009 & $12,774,822$ & $121,357.89$ & 9.5 \\
2010 & $13,995,300$ & $140,823.09$ & 10.1 \\
2011 & 15612,792 & $146,774.37$ & 9.4 \\
2012 & $16,189,823$ & $149,683.08$ & 9.2 \\
2013 & $16,833,297$ & $166,659.53$ & 9.9 \\
2014 & $18,004,958$ & $167,052.61$ & 9.3 \\
2015 & $18,872,696$ & $145,741.06$ & 7.7 \\
\hline
\end{tabular}

Fuente: SHCP, BIE del INEGI y Banco de México.

Los activos petroleros ofrecidos con la reforma de privatización en dicho sector en México, no resultaron tan rentables como se esperaba para atraer capitales, 
dada la baja internacional del precio del petróleo, y las inversiones que se han comprometido, serán para los próximos diez años. El problema del país es que ya no tiene más activos atractivos que ofrecer para que se siga demandando el peso para invertir en el país y así traer capitales. Desde hace tiempo se abrió la banca al capital extranjero, la minería, los ferrocarriles, los sectores prioritarios y estratégicos. Ello solo ha extranjerizado más al país, sin desarrollar la esfera productiva para sustituir importaciones y aumentar el valor agregado nacional de las exportaciones, por lo que no se ha avanzado en el ahorro y generación de divisas, para reducir el déficit de comercio exterior y cubrir el pago de las utilidades de tales inversiones, como de la deuda externa.

Los activos financieros se han despegado en relación al comportamiento de la economía real. Los activos financieros de 2009 a 2016 crecieron al $9.7 \%$ promedio anual, mientras el PIB en términos reales lo hizo en $3.1 \%$ promedio anual en dicho período (véase Cuadro 2 y Gráfica 1), dada la gran entrada de capitales al mercado de capitales y de dinero, como por la privatización y extranjerización de activos nacionales realizados a través de la bolsa de valores, así como por el diferencial de tasas de interés entre México y EUA.

Cuadro 2

México: Activos financieros, PIB, Relación Activos Financieros-PIB, 2007-2016

(Miles de millones de pesos)

\begin{tabular}{cccc}
\hline Años & Activos Financieros (AF)1 & PIB & AF/PIB $(\%)$ \\
\hline 2009 & $123,150.3$ & $12,774,822$ & 9.6 \\
2011 & $130,314.4$ & 13,995300 & 9.3 \\
2010 & $147,275.0$ & $15,612,792$ & 9.4 \\
2012 & $169,470.3$ & $16,189,923$ & 10.5 \\
2013 & $188,640.1$ & $16,833,297$ & 11.2 \\
2014 & $211,130.2$ & 18,004958 & 11.7 \\
2015 & $230,542.4$ & $18,872,616$ & 12.2 \\
2016 & $235,324.3$ & $19,103,568$ & 12.3 \\
\hline
\end{tabular}

1. Títulos de deuda emitidos en el mercado local. Se toman en cuenta activos de Instituciones Financieras, no financieras, Gobierno en general y los no residentes.

2. Ambos datos están en precios corrientes.

3. En el año de 2016, los AF son hasta agosto, y el PIB corresponde al segundo trimestre. Fuente: Banco de México e Inegi. 
Gráfica 1

Inversion extranjera directa e inversión de cartera

(2010-2016)

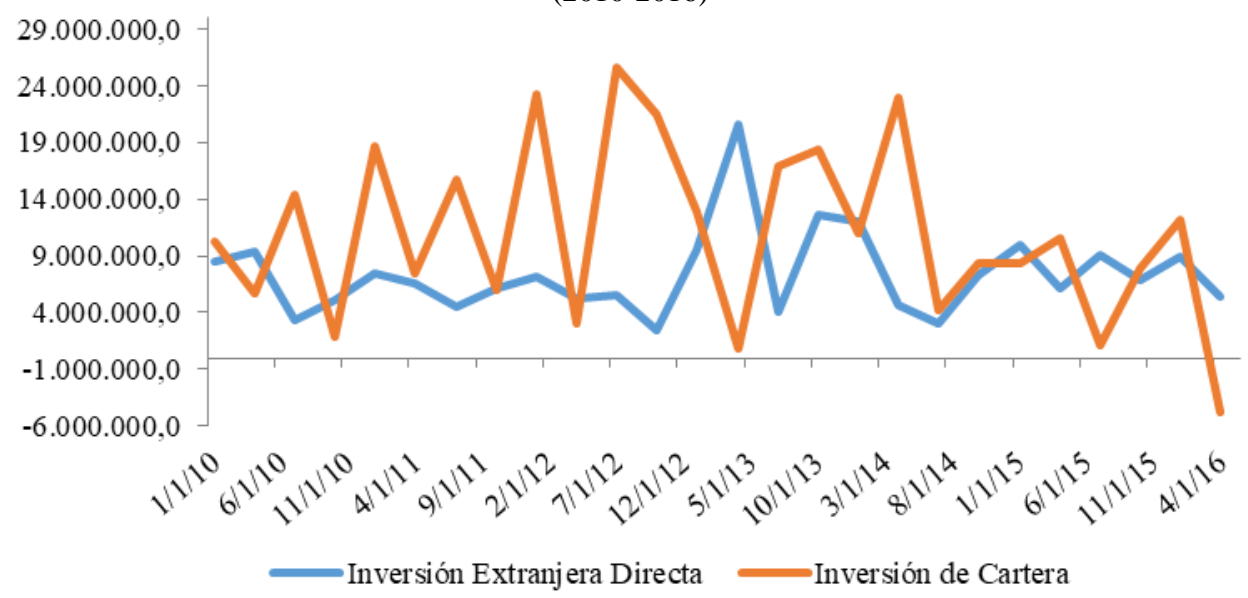

Fuente: Banco de México (2016).

\subsection{El mayor endeudamiento y la entrada de capitales impulsaron un bajo crecimiento, que no asegura condiciones de reembolso}

La entrada de divisas y de capitales (véase la cuenta de capitales, Cuadro 3) permitió incrementar el gasto del sector privado y del sector público. El impulso que ello generó sobre la actividad económica no fue significativo, debido al alto componente importado de la demanda derivado de la apertura comercial, como de la apreciación del tipo de cambio, incrementan el déficit de comercio exterior y reducen el efecto multiplicador interno sobre el ingreso nacional, además de comprometer las condiciones de reembolso de las obligaciones financieras internas y externas.

Cuadro 3

Algunos Indicadores de la Balanza de Pagos (miles de millones de dólares)

\begin{tabular}{c|c|c|c|c|c|c}
\hline & 2010 & 2011 & 2012 & 2013 & 2014 & 2015 \\
\hline Déficit Cta. Cte. & 5218 & 13397 & 16559 & 30322 & 24846 & 32381 \\
\hline Cta. de Capital & 48747 & 52778 & 54905 & 67767 & 57947 & 33826 \\
\hline
\end{tabular}

Fuente: Banco de México (2016).

La internacionalización de los mercados de capitales y la libre movilidad de capitales ha permitido acceder a los mercados internacionales, tanto a la banca como a las grandes empresas (Véase Gráfica 2), lo que significa cargas de pago de dichas deudas. Nos dice Kozul-Wright que "en una muestra de las economías emergentes, la deuda denominada en dólares de las sociedades no financieras aumentó en un $40 \%$, en promedio, de 2010 a 2014, y de 2007-2015, su proporción de servicio de la 
deuda también se elevó en un 40\%. Estas cifras sugieren que se está gestando una crisis bancaria sistémica (2016).

\section{Gráfica 2}

México: Deuda del sector bancario y de sociedades financieras no bancarias, 2010-2016 (millones de dólares corrientes)

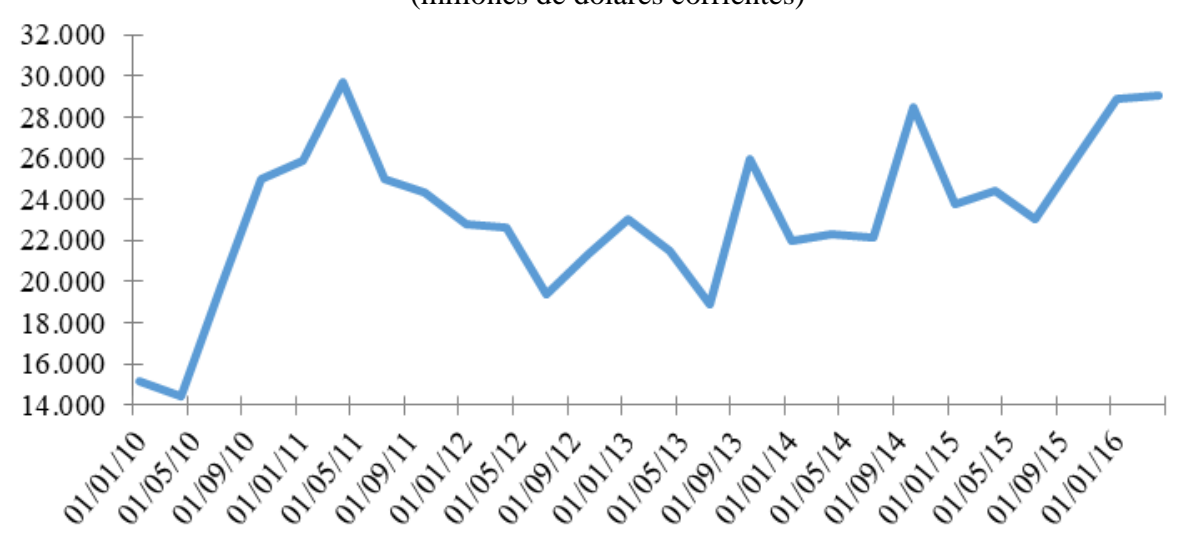

Fuente: Banco de México (2016).

La mayor liquidez que ha adquirido la economía y la banca, ha permitido aumentar la disponibilidad crediticia, no tanto para promover inversión productiva, sino sobre todo a otros sectores de la economía (Gráfica 3).

Gráfica 3

México: Crédito otorgado por la banca comercial según la actividad principal de los prestatarios, 2007-2016.

(Millones de Pesos)

4.000 .000

3.500 .000

3.000 .000

2.500 .000

2.000 .000

1.500 .000

1.000 .000

500.000

0
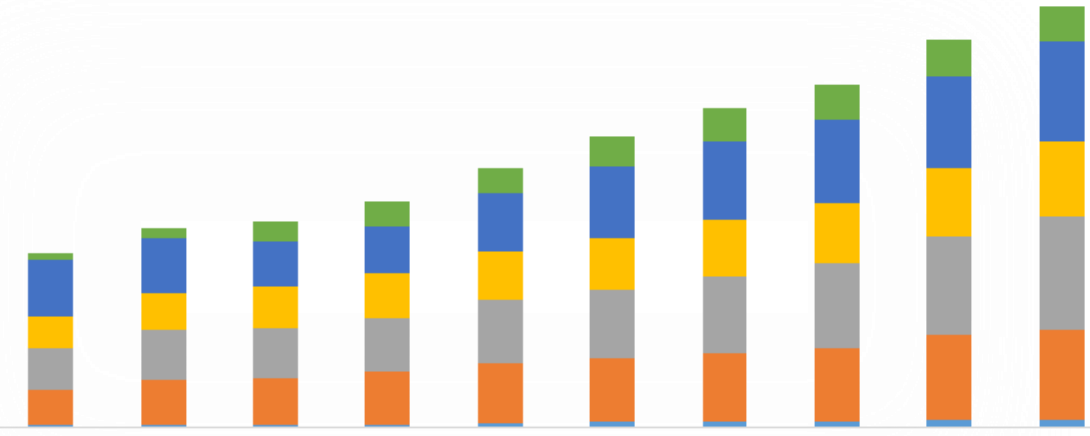

$2007 \quad 2008$

2009

2010

2011

2012

2013

2014

2015

2016

- Sector Primario

Sector Secundario

- Sector Terciario

- Vivienda

n Consumo

Estados y Muni cipios

Fuente: Banco de México (2016). 
El sector bancario y financiero en el contexto de la globalización, no ha sido funcional al sector productivo, ni al crecimiento económico. No hay expansión de créditos a la industria manufacturera al no haber expectativas de crecimiento, ni ganancias suficientes que garanticen el reembolso de los créditos. A su vez, las empresas dejan de demandar créditos para invertir a fin de no comprometer sus colaterales. Tal situación frena la creación de dinero a favor del proceso productivo (D-M-D').

Ante los problemas que enfrentan las empresas, reducen salarios para evitar pérdidas. Ello contrae consumo y el mercado interno, y lleva a las familias a demandar créditos. Sin embargo, la apertura comercial y la apreciación de la moneda, han llevado a que se incremente el consumo de bienes importados, lo cual ha roto cadenas productivas e incrementado el déficit de comercio exterior y reduce el ingreso de empresas. Ello lleva a la economía a depender de los créditos y de la entrada de capitales para mantener los niveles de gasto, inversión y consumo. Las políticas a favor de lo financiero, frenan el crecimiento económico e incrementan el endeudamiento y los problemas de insolvencia.

Las grandes empresas que se endeudan, o es para sortear sus problemas, o para especular, como para adquirir acciones de sus empresas y/o para adquirir otras empresas, pero no tanto para incrementar la capacidad productiva, dado el bajo crecimiento de demanda. Los créditos que se otorgan, se canalizan sobre todo a la esfera financiera, impulsando la financiarización, que es dinero que busca dinero sin pasar por el sector productivo (D - D'), lo que aumenta los desequilibrios entre el sector financiero y el sector productivo.

Al marginarse el desarrollo productivo, prosiguen las presiones sobre el déficit de comercio exterior y no se crea el reembolso de las obligaciones financieras que se derivan del mayor endeudamiento, como de la entrada de capitales (pago de utilidades royalties, pago de amortizaciones e intereses), por lo que aumenta más la dependencia creciente de entrada de capitales y la relación de endeudamiento.

\subsection{Presiones de la deuda sobre las finanzas públicas y el sector externo}

En México, la caída internacional del precio del petróleo, como de las exportaciones petroleras, han reducido los ingresos al sector público y de divisas, incrementado las presiones sobre las finanzas públicas y sobre el déficit del sector externo. A su vez la carga del servicio de la deuda pública se ve incrementada, tanto por el mayor monto de la deuda, como por la devaluación y el aumento de la tasa de interés en que está colocada dicha deuda. Las transferencias al exterior por concepto del pago de la deuda, y por remisiones y utilidades que realiza el capital externo que se ubica en el país, han aumentado y así el déficit de cuenta corriente de balanza de pagos, lo que resta recursos para impulsar el crecimiento. Ello se da en un contexto donde está disminuyendo la entrada de capitales (inversión directa e indirecta), lo 
que ha incrementado los problemas financieros del sector externo, obligando a la economía a recurrir al endeudamiento externo. La economía ya no cuenta con activos atractivos para atraer capitales, ni tampoco con capacidad para generar superávit de comercio exterior en condiciones de crecimiento, para asegurar el pago de la deuda. Ello obliga al gobierno a restringir el gasto público para obtener superávit primario para cubrir el pago de la deuda, pero no lo logra, debido a que ello disminuye el ingreso de las empresas e individuos y del propio gobierno.

Asimismo, le es difícil reducir el déficit de cuenta corriente a través de disminuir el déficit de comercio exterior, dados los problemas estructurales que están detrás de dicho déficit (rezagos productivos, bajo crecimiento de la productividad, altos coeficientes importados), como por la caída internacional del precio del petróleo, y del crecimiento de las exportaciones, lo que le dificulta encarar el pago de la deuda externa. No es fácil acceder a los mercados financieros para obtener financiamiento barato, y menos ante el cambio de la política monetaria en EUA. Ante ello, el gobierno tiene que ofrecer mayores tasas de interés para colocar deuda en los mercados, lo que acentuará más las presiones sobre las finanzas públicas, lo que seguirá aumentando la deuda y la relación de endeudamiento y el riesgo país.

El sector externo pasa a actuar como cuello de botella, ya que se deja de contar con divisas para financiar el déficit de cuenta corriente, como para mantener la estabilidad cambiaria, por lo que se obliga a instrumentar políticas contraccionistas.

Ante el riesgo de no pago, las corredurías internacionales tienden a bajar el grado de inversión, lo que presiona sobre la tasa de interés de nuevos créditos, y en consecuencia sobre la carga del servicio de la deuda e impacta a todos los sectores endeudados. Se aumenta los recursos a los acreedores a costa de reducir su capacidad de inversión y de gasto, contrayendo más la actividad económica. Se descapitalizan los deudores y aumenta el poder de los acreedores y la desigualdad del ingreso.

Al contraerse el mercado interno, el sector privado en su conjunto no demanda deuda para invertir, por lo que termina reduciéndose más la actividad económica. Nos dice Jan Toporowski que "una reducción de la deuda del gobierno, sin incremento de la deuda privada, resultaría en una reducción en el ingreso nacional" (2014). Al tratar de reducir su deuda el sector público, a través de disminuir su gasto contrae el ingreso nacional y el de las empresas, y si éstas no incrementan su gasto y su deuda, más se contrae la actividad económica.

No es a través de reducir gasto público, ni empleo, ni salarios, como se saldrá de los problemas que enfrentamos. Ello contrae demanda, mantiene baja la inflación, como el crecimiento del ingreso nacional, por lo que acentúa los problemas de insolvencia y de mayor deuda, lo que tiende a desestabilizar de nuevo a la banca. Ante otra crisis bancaria-financiera, el gobierno no podrá actuar, dados sus altos niveles de endeudamiento. Los bajos precios del petróleo seguirán, y la devaluación 
del peso y el alza de la tasa de interés, presionan sobre las finanzas públicas y sobre el monto de la deuda. Ello evidencia que no se reduce la deuda disminuyendo el gasto público.

Cuando todos quieren reducir deuda, contrayendo su gasto e inversion, restringen la actividad económica y con ello sus ingresos, por lo que se acentúan sus problemas de pago de la deuda, y se incrementa la relación de endeudamiento, complicando ello más su capacidad de gasto, por lo que se cae en más deuda, para pagar deuda.

Las políticas macroeconómicas de 'estabilidad', junto a los bajos salarios, la baja demanda y del comercio internacional, han ocasionado baja inflación (y deflación en varias economías desarrolladas), lo que va aparejado con el incremento de los precios de los activos financieros. Tales precios terminarán ajustándose, al evidenciarse que no tienen sustento real que los mantenga, más allá de los flujos de capital que se dirigen a dicho sector.

\subsection{Baja inflación, bajo crecimiento económico, problemas de endeudamiento y financiarización de las economías}

Los problemas de deuda se presentan cuando ésta no se usa para potenciar el crecimiento del ingreso nacional y así asegurar el reembolso de la deuda, o cuando promueve un crecimiento con alto componente importado y bajo efecto multiplicador interno, y genera presiones sobre el sector externo, por lo que no se incrementa el ingreso de empresas e individuos en una proporción tal que asegure el reembolso de la deuda.

Cuando el ingreso crece menos que el costo del crédito y de los ritmos de endeudamiento, y cuando no se generan divisas suficientes para cubrir la carga de la misma (en el caso de la deuda externa), se crean problemas de pago que frenan el crecimiento de la economía. En este caso, la economía cae en el efecto Ponzi, de pedir deuda para pagar deuda, así como en políticas monetarias y fiscales restrictivas, dirigidas a generar ahorro forzoso para generar condiciones de pago de la deuda, a costa de sacrificar el crecimiento, lo que recrea los problemas de insolvencia.

El problema de la deuda del gobierno surge cuando se endeuda en otra moneda que no emite, y/o cuando pierde el control de la moneda y se compromete a la convertibilidad de la misma a un tipo de cambio estable. En tal situación no puede monetizar el pago de la deuda, ni el déficit fiscal. (Wray, 2012, p. 146-147)

Como consecuencia de la crisis de 2008-09 vuelve a crecer la deuda del sector público y del sector privado (Véase Gráfica 4). Además hay que considerar que un alto porcentaje de la deuda pública interna ha sido adquirida por inversionistas extranjeros, dado el diferencial de tasas de interés interna versus externa. 
La globalización y la política macroeconómica acentúan la financiarización y la fragilidad...

Gráfica 4

México: Deuda Pública y Privada, 2010-2016.

(\% del PIB)

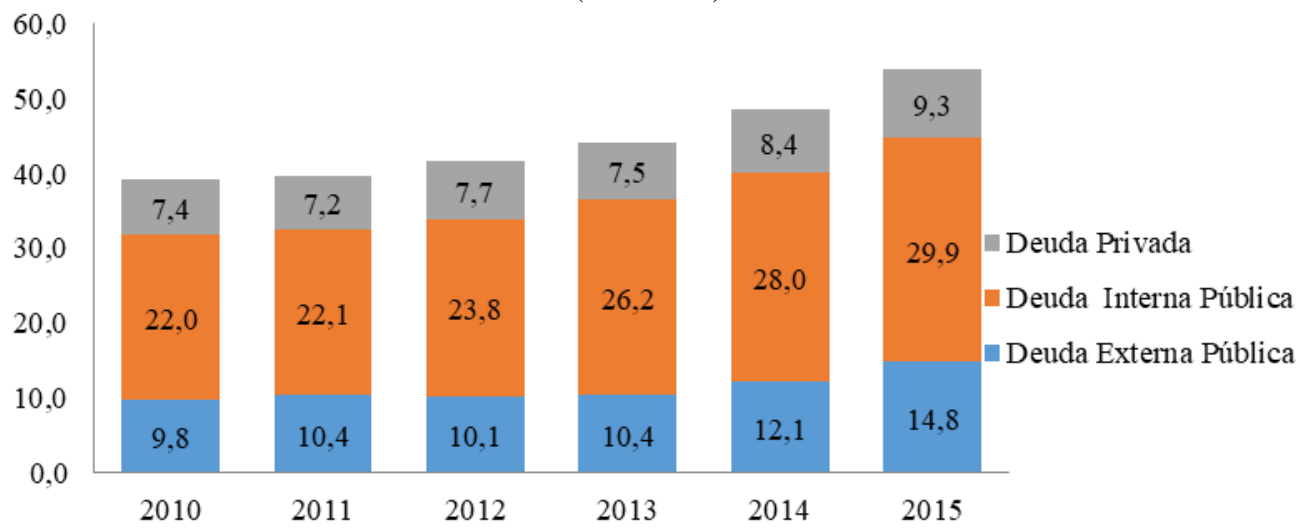

Fuente: Banco de México y SHCP (2016).

Ante la volatilidad de la inversión de cartera y de la Inversión Extranjera Directa (Véase Gráfica 1) se opta por asegurar la entrada de divisas a través de la deuda externa. De ser la deuda pública externa 24,319.4 millones de dólares en 2008 en México, pasó a ser 193,724.4 millones de dólares en septiembre de 2017. (SHCP) En menos de 9 años se multiplicó por 8 veces. La deuda pública total se multiplicó por 3.3 veces de 2009 a 2016 (Cuadro 4), mientras el PIB real solo creció en 2.9\% promedio anual, evidenciando que dicha deuda no fue para impulsar la inversión y la dinámica económica.

Cuadro 4

Tabla. México: Deuda Pública Total, PIB y su Relación, 2009-2015.

(Millones de Pesos)

\begin{tabular}{c|c|c|c}
\hline Años & Deuda Total & $\begin{array}{c}\text { PIB } \\
\text { (Nominal) }\end{array}$ & $\begin{array}{c}\text { Deuda } \\
\text { Total/PIB \% }\end{array}$ \\
\hline 2009 & $2,887,880.10$ & $12,774,822$ & 22.6 \\
\hline 2010 & $3,080,885.00$ & $13,995,300$ & 22 \\
\hline 2011 & $4,848,230.90$ & $15,612,792$ & 31 \\
\hline 2012 & $5,352,794.70$ & $16,189,823$ & 33.1 \\
\hline 2013 & $5,943,288.00$ & $16,833,297$ & 35.3 \\
\hline 2014 & $6,947,446.40$ & $18,004,958$ & 38.6 \\
\hline 2015 & $8,160,589.90$ & $18,872,696$ & 43.2 \\
\hline 2016 & $9,693,217.50$ & $20,253,697$ & 47.8 \\
\hline
\end{tabular}

Fuente: INEGI, Banco de México y SHCP. 
En el Cuadro 5 podemos ver como a partir de 2008 ha venido disminuyendo la participación de la inversión pública en el PIB. De representar el 5.9\% en dicho año, pasó a 3.0\% en 2016.

Las presiones crecientes que se derivan de la carga del servicio de la deuda interna y externa, por la devaluación del peso, como por el alza de la tasa de interés, como por el mayor monto de la deuda, llevan al gobierno a restringir la inversión para evitar caer en déficit fiscal. Se sacrifica el crecimiento, para cumplir con los acreedores y no violentar los llamados 'fundamentos' macroeconómicos.

\section{Cuadro 5}

México: Inversión Pública, PIB y Relación Inv. Púb / PIB

(Millones de Pesos, precios constantes de 2008)

\begin{tabular}{c|c|c|c}
\hline Años & Inversión Pública (IP) & PIB & IP/PIB \% \\
\hline 2007 & 603,413 & $12,223,516$ & 4.9 \\
\hline 2008 & 712,411 & $12,068,536$ & 5.9 \\
\hline 2009 & 631.529 & $11,921,331$ & 5.3 \\
\hline 2010 & 704,995 & $12,450,003$ & 5.6 \\
\hline 2011 & 639,081 & $12,971,000$ & 4.9 \\
\hline 2012 & 584,363 & $13,417,269$ & 4.3 \\
\hline 2013 & 607,164 & $13,556,911$ & 4.5 \\
\hline 2014 & 559,779 & $13,917,167$ & 4 \\
\hline 2015 & 469,461 & $14,321,589$ & 3.3 \\
\hline 2016 & 440,825 & $14,591,020$ & 3 \\
\hline
\end{tabular}

Fuente: Elaborado con base a BIE del Inegi.

\subsection{Bajo crecimiento económico, aumento de la deuda y de los mercados de capitales, van aparejados}

Las economías desarrolladas no logran retomar el crecimiento que tenían antes de la crisis. Los mercados de capitales se recuperaron por la inyección de liquidez y las bajas tasas de interés instrumentadas por los bancos centrales de los países desarrollados. Sin embargo, ello no se ha traducido en crecimiento de la inversión y de la actividad económica en forma sostenida, dado que la política económica continúa impulsando la financiarización de las economías.

En muchas economías emergentes el mercado de capitales tuvo un buen desempeño, dadas las condiciones de estabilidad cambiaria que el alza del precio internacional de las materias primas y del petróleo, así como por la entrada de 
capitales que los procesos de privatización estimulaban. A ellos se sumaba la flexibilidad de la política monetaria en EUA y el diferencial de tasas de interés entre las economías emergentes con la de EUA, que promovió entrada de capitales a los mercados de dinero y de capitales. Sin embargo, en el caso de México, el impacto positivo que generaron los altos precios internacionales del petróleo en las finanzas públicas y en el sector externo, junto a la entrada de capitales a los mercados financieros, no se tradujo en flexibilidad de la política monetaria y fiscal a favor del crecimiento económico y del empleo. Continúa la política a favor de lo financiero (austeridad fiscal, las altas tasas de interés y la apreciación de la moneda nacional), que resta competitividad a la producción nacional y a la dinámica de ésta. Al no haber estímulos de inversión en el sector productivo, dada la contracción de demanda derivada de las políticas de austeridad fiscal, como por la desaceleración del comercio internacional, se reduce el ingreso de empresas e individuos y del gobierno, y aumentan las presiones sobre la balanza de comercio exterior, como los niveles de endeudamiento interno y externo de la economía.

El aumento del precio de las acciones no es tanto por las mayores ganancias de las empresas que cotizan en dichos mercados, dada la desaceleración de la actividad económica, sino por la mayor liquidez inyectada al mercado de capitales, que al demandar acciones se incrementa su precio. Las bajas tasas de interés de los bonos públicos, lleva a los inversionistas a adquirir acciones, por lo que se incrementan su precio y de ahí el auge de las bolsas en los países desarrollados. Muchos inversionistas han invertido en los mercados de capitales de economías emergentes, lo que ha aumentado los índices de cotización de éstos. Ello refleja la fragilidad de dichos mercados, pues el boom bursátil no tiene sustento más que el flujo de capitales a dicho sector.

La Bolsa Alemana en 2015 mostraba un crecimiento de 35\% en relación al nivel que tenía en 2007, antes de la crisis. El Índice Nikkei de Japón mostraba un aumento de 23\% para igual período, y Standard and Poor's de Estados Unidos un aumento de $33.4 \%$ y la BMV de México un crecimiento de 47\% (Véase Cuadro 6). De 2009 a 2015 la BMV creció en 43.6\%, mientras el PIB real lo hizo solo en $20.8 \%$, que implica un crecimiento de $3.1 \%$ promedio anual y con una inflación promedio anual de $3 \%$ en dicho período.

El Dow Jones a inicios de julio de 2016 había aumentado 177\% en relación a su nivel más bajo cuando la crisis de 2009, evidenciando que los bancos centrales inyectan liquidez a los mercados financieros para favorecer el precio de los activos financieros y así a los poseedores de éstos activos. (Krugman, 2016) Al contrastar 
esta dinámica con el crecimiento del PIB, se evidencia que la política monetaria flexible ha favorecido al sector financiero y no a la economía real.

\section{Cuadro 6}

Tabla. Argentina, Brasil, Alemania, Japón, EUA y México: Comportamiento de las Bolsas de

Valores, 2007-2016

(Valores en distintas divisas)

\begin{tabular}{c|c|c|c|c|c|c}
\hline Años & $\begin{array}{c}\text { Argentina } \\
\text { Merval } \\
\text { Index }\end{array}$ & $\begin{array}{c}\text { Brasil } \\
\text { Bovespa } \\
\text { index }\end{array}$ & Alemania & $\begin{array}{c}\text { Japón } \\
\text { Nikkei }\end{array}$ & México $^{1}$ & E.U.A \\
index & INC index & S\&P 100 \\
\hline 2007 & $2,168.23$ & $63,886.00$ & $8,010.89$ & $15,413.37$ & $29,713.72$ & 689.40 \\
\hline 2008 & $1,076.58$ & $37,550.00$ & $4,754.22$ & $8,716.28$ & $26,859.90$ & 426.45 \\
\hline 2009 & $2,316.19$ & $68,588.00$ & $6,002.29$ & $10,707.51$ & $25,306.03$ & 518.95 \\
\hline 2010 & $3,523.19$ & $69,304.00$ & $6,914.19$ & $10,303.13$ & $33,285.89$ & 565.12 \\
\hline 2011 & $2,425.62$ & $56,754.00$ & $5,867.03$ & $8,434.90$ & $36,340.53$ & 573.01 \\
\hline 2012 & $2,839.84$ & $60,952.00$ & $7,612.39$ & $10,406.36$ & $40,037.19$ & 636.17 \\
\hline 2013 & $5,406.70$ & $51,507.00$ & $9,586.53$ & $16,269.22$ & $42,060.97$ & 820.97 \\
\hline 2014 & $8,444.88$ & $50,007.00$ & $9,883.10$ & $17,702.12$ & $42,644.21$ & 918.61 \\
\hline 2015 & $11,734.00$ & $43,349.00$ & $10,855.17$ & $19,070.83$ & $43,770.96$ & 919.78 \\
\hline 2016 & $17,123.48$ & $60,644.00$ & $10,549.69$ & $16,913.60$ & $45,765.03$ & 958.48 \\
\hline
\end{tabular}

* Con base a las estadísticas del Banco de México y la anualidad se obtuvo mediante una media simple

** Los valores que se presentan en las tablas están en el tipo de cambio de cada país, Los datos de 2016 corresponden a Octubre 6.

Fuente: Elaborado con base a Quanti.

Las Bolsas de Argentina y Brasil muestran en 2016 (Véase Cuadro 6) un gran crecimiento respecto al año anterior, a diferencia de Alemania y Japón que muestran caídas, y Standard and Poor's un ligero aumento de 4.2\%, evidenciando la fuerte especulación que se da en Argentina Y Brasil reflejan las expectativas de mayores privatizaciones que los nuevos gobiernos en tales países están abriendo al capital financiero, pero esos boom no cuentan con las bases reales que sustenten las ganancias ficticias ofrecidas por tales mercados, dadas las fuertes caídas de su actividad económica (Gráfica 5). Satyajit Das señala que "en economía y finanzas, los activos sobrevalorados y los excesivos niveles de deuda no conducen a finales felices" (2016). 
La globalización y la política macroeconómica acentúan la financiarización y la fragilidad...

Gráfica 5

Argentina, Brasil y México: Producto Interno Bruto, 2008-2015

(Tasa de crecimiento)

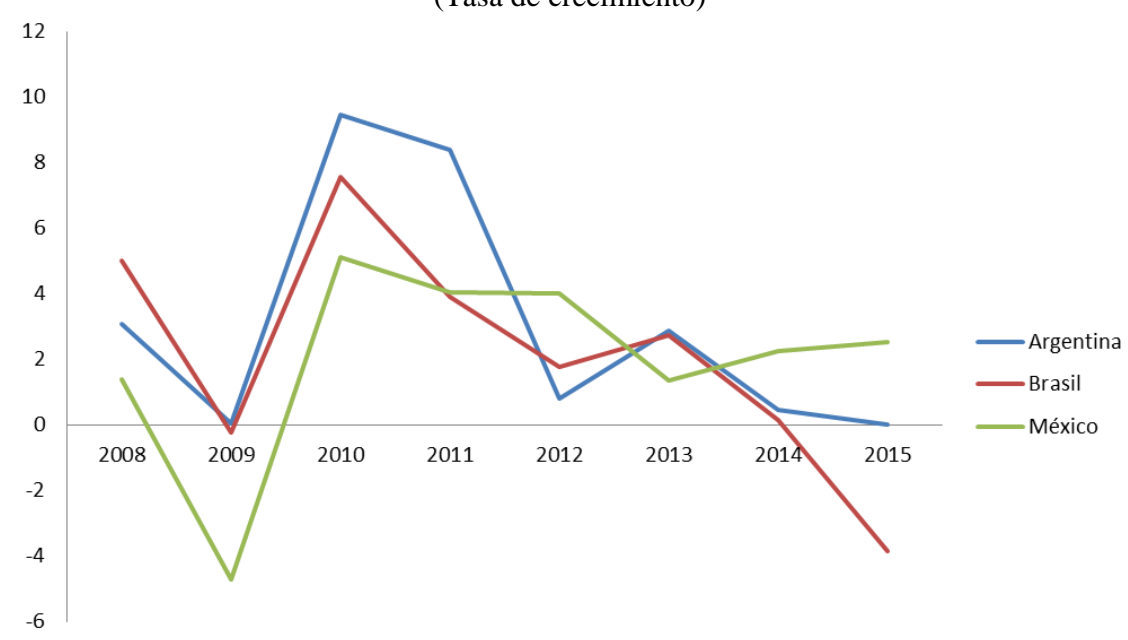

Fuente: Banco Mundial, excepto * tomado del Indec (2006).

Ante la falta de inversión atractiva en el sector productivo, y ante el riesgo que implica la inversión financiera, el sector de bienes raíces ha pasado de nuevo a ser opción para muchos inversionistas en varios países, lo que lleva a aumentar el precio de estos bienes. El autor antes citado señala que "los precios de los bienes raíces han aumentado a nivel mundial con los inversionistas que compran para adquirir flujos de ingresos de alquiler para diversificarse de los activos financieros de bajos ingresos" (Das, 2016).

Mientras siga contraída la demanda y las exportaciones, el capital seguirá canalizándose a la especulación en el mercado de capitales, o en bienes raíces generándose burbujas, las cuales explotarán cuando cambien las expectativas de los agentes que realizan tales inversiones. El mercado de capital está sujeto a las expectativas y decisiones de los inversionistas extranjeros y nacionales, donde el comportamiento de las condiciones internas y externas son tomadas en cuenta.

Hay que recordar que toda burbuja especulativa es seguida por una crisis que revienta dichas burbujas debido a que no hay condiciones reales que las sustenten. Al cambiar las expectativas de la economía, y al dejar ésta de ofrecer atractivos de inversión, al evidenciarse que no tiene sustento interno para convalidar los altos precios de los activos financieros, el capital sale y se desploma la Bolsa.

En contextos de presiones sobre las finanzas públicas y sobre el sector externo, como sobre los mercados financieros internacionales, y crecientes niveles de endeudamiento interno y externo, las economías nacionales pasan a ser altamente vulnerables. 
Como consecuencia de la caída internacional del precio del petróleo, observamos que la cuenta de capitales de balanza de pagos disminuye en 2014 y mucho más en 2015 (véase Cuadro 3). Asimismo, en el Cuadro 2, se observa que los Activos Financieros casi no aumentaron en 2014 en relación a 2013 y caen drásticamente en 2015. Dicha relación de ser 10.1 respecto al PIB en 2010, pasa a ser de $7.7 \%$ en 2015 .

La conjugación de baja inflación, con bajo crecimiento económico, con crecimiento de los niveles de endeudamiento, la participación de los activos financieros en el PIB, y el crecimiento del mercado de capitales, es insostenible, al no haber condiciones internas y/o entrada de capitales que lo mantenga.

\section{No hay condiciones internas y externas para recuperar el crecimiento y mantener la libre movilidad de mercancías y capitales y la financiarización de las economías}

\subsection{No hay perspectivas que las economías desarrolladas salgan del bajo crecimiento en que se encuentran}

Al parecer la economía mundial continuará como se ha comportado en los últimos años. No hay perspectivas de que los países de la zona euro resuelvan sus problemas de endeudamiento y de crecimiento. Persisten los problemas de pago en Grecia y sigue creciendo la deuda en todos ellos, que ponen en jaque a la economía Italiana, tercer economía de dicha zona. Japón, a pesar de trabajar con tasa de interés negativa, tampoco crece, ni sale del estancamiento que ha mantenido desde los años 90. Ahora, con tal política monetaria, como con la devaluación del yen y el impulso a la industria de la construcción para la realización de los Juegos Olímpicos en 2020, pretenden reactivar su economía (Hamada, 2016). Desde que empezaron los problemas de estancamiento y deflación se han realizado diversos intentos fiscales y monetarios, sin alcanzar los objetivos de salida de tal situación, dada la alta propensión al ahorro de las familias japonesas.

China no tiene condiciones internas y externas para retomar la dinámica de crecimiento de dos dígitos que tuvo por décadas. Ante la caída de sus exportaciones China ha estado impulsando la estrategia de crecimiento hacia el consumo interno. Señala Steinbock que "en los tres primeros trimestres del año, el consumo representó el 70 por ciento de crecimiento del PIB, casi dos veces más que el 37 por ciento atribuido a la inversión" (2016). Es difícil qué, con tal estrategia, China logre el crecimiento que le permitió la estrategia de crecimiento hacia fuera, debido a que le origina presiones sobre su balanza de comercio exterior, y crecimiento de endeudamiento, como ya está aconteciendo. El mismo autor señala que "en los últimos dos años, la morosidad de los bancos casi se ha duplicado al 6 por ciento", lo que terminará limitando la dinámica del consumo. 
La economía de EUA en los últimos años ha venido creciendo alrededor del $2 \%$ promedio anual. Ahora con el nuevo gobierno de Donald Trump al parecer se expandirá la inversión pública y se establecerán políticas proteccionistas, lo cual está generando expectativas de crecimiento. Sin embargo, ello no implica que dicha economía pueda volver a ser el motor de la economía mundial, como lo fue en décadas pasadas, debido a que de instrumentarse la política proteccionista impulsará el efecto multiplicador hacia adentro y no hacia fuera.

El resto de los países desarrollados y la mayoría de las economías emergentes continúan con la misma política de libre comercio y políticas de austeridad fiscal que los llevó a la crisis y al círculo vicioso de sobreendeudamiento y lento crecimiento en que se encuentran, que impide condiciones de reembolso. Al no crecer tales economías, hace que continúe el bajo crecimiento del comercio mundial. El comportamiento de los bajos precios internacionales de las materias primas y del petróleo, dependerá de que tanto crezca la economía de EUA y el resto de los países desarrollados. Ello determinará los niveles de ingreso de divisas de las economías latinoamericanas, como el comportamiento de sus variables macroeconómicas, y sobre sus monedas.

Al seguir la libre movilidad de mercancías y capitales, así como los objetivos de baja inflación y la búsqueda de los fundamentos macroeconómicos 'sanos', para favorecer los deseos de 'estabilidad' del sector financiero, no hay viabilidad de flexibilizar la política mentaría y fiscal a favor del crecimiento en las economías de América Latina. Confían en que las reformas estructurales de privatización y extranjerización y de reducción de los derechos laborales de los trabajadores, generen condiciones de acumulación para retomar el crecimiento. A pesar que muchos países llevan años en eso, no logran tales objetivos.

\subsection{La financiarización y las crisis recurrentes}

El bajo crecimiento económico, los altos niveles de endeudamiento, la dependencia creciente a la entrada de capitales y las crisis recurrentes, han sido resultado de las políticas económicas predominantes que impulsan la financiarización de las economías, ya que afecta la dinámica de acumulación del sector productivo y aumentan las presiones sobre las variables macroeconómicas.

La canalización de los recursos hacia lo financiero, ha generado burbujas especulativas que no son validadas por las condiciones de acumulación del sector productivo. La ampliación de la brecha entre lo financiero y el sector productivo, termina haciendo insostenible las ganancias ofrecidas en el mercado de capitales, por lo que los capitales buscan otras opciones de inversión para protegerse, por lo que termina cayendo el precio de los activos financieros. 
El auge de lo financiero hace que prosiga la hegemonía de dicho sector, no obstante que ha sido el causante de las crisis recurrentes que se enfrentan. Tal situación mantiene el clima de incertidumbre y vulnerabilidad, dado que el precio de las acciones está sujeto al acontecer mundial y nacional, como a los flujos de capitales.

Los mercados de capitales crecen a sobresaltos, debido a que dicho mercado está sujeto a las perspectivas que los agentes financieros tengan del acontecer internacional, como de los problemas de las principales economías y mercados de mercancías y divisas, ya que ello incide en la valorización buscada por ellos. El contexto de bajo crecimiento económico, aunado al crecimiento de deuda y de la relación de endeudamiento, representan un riesgo para el crecimiento mostrado por los mercados de capitales. Señala Feldstein que "hoy los precios de las acciones, medidos según la relación de precio a ganancias de los 500 principales valores de S\&P, se encuentran cerca de un 60\% por encima de su promedio histórico" (2016).

La financiarización es desestabilizadora y genera crisis recurrentes, pues no genera riqueza (Fasianos et al., 2016). Dicho mercado se valoriza mientras los capitales fluyen a él. Cuando dejan de fluir, éste se desvaloriza. Cualquier problema que se manifieste en una gran economía, o en algún mercado financiero, rápidamente trastoca el funcionamiento y desempeño de todos ellos, dada la interrelación existente entre ellos, que ha originado la globalización.

A pesar que las prácticas financieras especulativas terminan en crisis, continúan desarrollándose, pues los rescates a las crisis han operado a favor de la banca y los mercados de capitales, debido al poder económico y político de dicho sector. Ello hace que siga imperando la política económica a su favor y las regulaciones instrumentadas no frenan el desarrollo de las prácticas especulativas.

Las economías no pueden ser comandadas por lo financiero, pues ello distorsiona la asignación de recursos, relega las condiciones endógenas de acumulación y nos lleva a depender de la entrada de capitales, lo que nos hace más vulnerables y siempre termina en crisis (Epstein y Montecino, 2016).

Mientras no se limite y regule drásticamente el funcionamiento del sector financiero, éste seguirá siendo el hegemónico, imponiendo políticas a su favor y con sus prácticas especulativas que desquician y distorsionan el funcionamiento de las economías.

\subsection{Al no haber condiciones endógenas para viabilizar el libre comercio, la libre movilidad de capitales y la financiarización de las economías en desarrollo, y al no haber entrada de capitales suficientes, tales políticas pasan a ser insustentables}

La política económica predominante nos ha alejado de las bases materiales necesarias para impulsar un crecimiento endógeno, auto-sostenido, sino por el 
contrario, hemos caído en crecientes niveles de endeudamiento y dependencia creciente del comportamiento de las variables externas. Al no haber entrada de divisas y capitales suficientes, se compromete el financiamiento del déficit de cuenta corriente de la balanza de pagos, lo que implica no poder cubrir el pago del servicio de la deuda externa, ni el déficit de comercio exterior, ni mantener la estabilidad cambiaria, como ha venido aconteciendo. Ello obligará a renegociar el pago de la deuda externa, como a contraer la actividad económica para restringir importaciones y ajustarlas al nivel de las exportaciones. Al no poder financiar el crecimiento de las importaciones, se afecta el consumo nacional, dado el alto componente importado de los productos manufactureros, como las importaciones de granos básicos, lo que impactará sobre precios y el nivel de vida de la población.

Al no existir suficientes flujos de divisas (dada la caída de exportaciones y de los precios del petróleo y de las materias primas) y capitales, se compromete la libre movilidad de mercancías y capitales. Señala Ugo Panizza, que "la globalización financiera exige una red de seguridad financiera mundial más fuerte" (2016), y la cuestión es que a pesar que el FMI la pueda proporcionar, cada vez son más las demandas de financiamiento para viabilizar dicho proceso, evidenciando que no existen condiciones endógenas que lo sustenten, por lo que termina fragilizándose y generando crisis cada vez mayores, difíciles de resolver. No hay viabilidad de que vengan 'ayudas' o apoyos por parte de los organismos financieros internacionales, dadas las demandas generalizadas de recursos que se requieren y requerirán, y aunque éstos fluyan, el problema es los condicionantes que impondrán a dichos créditos, pues no pueden seguir insistiendo en libre comercio, libre movilidad de capitales y disciplina fiscal que son los causantes de los problemas de insolvencia.

\section{Las contradicciones y problemas presentes cuestionan a las políticas que los han generado}

\subsection{Cuestionamientos a la globalización y a la financiarización de las economías y la demanda por cambios de las políticas predominantes}

La generalización de la problemática económica mundial, terminará desestabilizando los mercados financieros y de divisas, que exacerbará más la contracción económica, como el descontento económico político y social, por lo que crecen las demandas para que se replantee la política económica predominante.

Cada vez crece más el descontento frente a las políticas de libre movimiento de mercancías y capitales, como contra las políticas macroeconómicas que le acompañan, dados los problemas de estancamiento, recesión, bajo crecimiento económico, desempleo y subempleo, bajos salarios, creciente desigualdad del ingreso y alta fragilidad de las economías, que las hace altamente vulnerables al entorno internacional. Los problemas económicos debilitan a los defensores de las políticas económicas predominantes. Está el ejemplo del Brexit, como los llamados 
movimientos 'populistas' presentes en varias partes del mundo, que demandan cambio de dichas políticas, y lo que llevó al triunfo de Donald Trump a la Presidencia de Estados Unidos.

No solo se cuestionan los tratados de libre comercio y las políticas de austeridad fiscal, sino también la autonomía de los bancos central, que le quitó a los gobiernos el control de la moneda, para subordinar la política económica a los dueños del dinero, y para achicar el tamaño y participación de los gobiernos en la economía. La nueva Primer Ministro del Reino Unido, Theresa May pasó a cuestionar el desempeño de su banco central, al decir que los dueños de los activos financieros se han enriquecido y los que no los tienen, han sido perjudicados. (Davies, 2016) Hasta la Margarte Thatcher, impulsora del neoliberalismo en su país, se opuso en su momento a la independencia del banco central del Reino Unido y decía que no permitiría que banqueros no electos controlaran la política monetaria (Davies, 2016) En los países miembros de la Unión Monetaria Europea crece también el rechazo al Banco Central Europeo, dados los limitantes de manejo de política económica que enfrentan los gobiernos para satisfacer las demandas nacionales (Issing, 2016).

Tales cuestionamientos evidencian la importancia de la moneda y de la política monetaria en el desempeño económico de los países. Gobierno que no controla la moneda, no tiene política monetaria, cambiaria y fiscal para el crecimiento. Se subordina toda la política económica a la estabilidad monetariacambiaria, a costa de sacrificar el objetivo de crecimiento y de empleo.

\subsection{El gobierno requiere controlar la moneda, incrementar el gasto, regular al sector financiero y el movimiento de mercancías y capitales}

El principal obstáculo al crecimiento y uno de elementos que ha incrementado la deuda pública e impulsado la financiarización de las economías, lo ha representado la pérdida del control de la moneda por parte del gobierno. Ello llevó a que los gobiernos dejaran de tener política monetaria, fiscal y cambiaria a favor del crecimiento. El gobierno y el sector productivo pasaron a depender del financiamiento interno y externo para su desempeño, lo que les ha permitido al sector bancario y financiero crecer.

Los gobiernos deben recuperar el control de la moneda, para tener política económica para encarar y resolver los problemas de sus economías. El gasto público debe ser deficitario para incrementar demanda e inversión productiva. Ello no sería inflacionario si el gasto público se canaliza a incrementar la productividad y la capacidad productiva y el empleo, para sustituir importaciones para asegurar alto efecto multiplicador interno a favor de la producción nacional para evitar déficit de comercio exterior y poder incrementar el ingreso de empresas e individuos y del propio gobierno, pues al aumentar el ingreso nacional se incrementan los ingresos 
tributarios. El ingreso nacional debe aumentar por arriba del costo de la deuda, para asegurar capacidad de pago y reducir los niveles de endeudamiento. Sin crecimiento económico, no se podrá pagar la deuda. Solo aumentando el ingreso de empresas e individuos y del propio gobierno, se tendrá condiciones para que éstos encaren el pago de la deuda. Nos dice Toporowski que "la única forma efectiva y sostenida de manejar la deuda es asegurando que la inversión en la economía sea suficientemente alta para que la deuda sea servida" (2013).

El Estado debe retomar el control de la moneda y el manejo de la política económica a favor del sector productivo y del empleo. Para ello, debe además revisar y regular la libre movilidad de mercancías y capitales, así como al sector bancariofinanciero. Se tiene que evitar presiones sobre el sector externo y acciones especulativas de salida de capitales que desquicien la economía y debe hacer funcional al sector bancario a la esfera productiva, para encarar los desequilibrios productivos que presionan sobre el déficit de comercio exterior y nos llevan a depender de la entrada de capitales.

\section{A manera de conclusión}

Mientras el sector financiero siga siendo el hegemónico, no hay viabilidad de cambiar la política económica predominante de libre movilidad de mercancías y capitales, altas tasas de interés y austeridad fiscal. Es decir, no hay viabilidad de flexibilizar la política económica a favor de la esfera productiva y del empleo, lo cual nos ha condenado a estar sujetos al comportamiento de las variables externas. Ante el escenario actual de desaceleración de las economías y del comercio mundial, nuestras economías no tienen condiciones de recuperar el crecimiento ya sea hacia el mercado externo, o hacia el mercado interno.

Al no tener entrada de capitales suficiente, no hay viabilidad de financiar el déficit fiscal y del sector externo, lo que pasa a comprometer la libre movilidad de mercancías y capitales y el libre desempeño del mercado de capitales. Las economías caen en crisis económicas recurrentes ante su incapacidad de encarar sus problemas endógenos, como exógenos.

Los problemas de bajo crecimiento, desempleo, bajos salarios y creciente desigualdad del ingreso, así como las crisis económicas recurrentes, están cuestionando la globalización y la política que le acompaña y se demanda políticas económicas que reviertan tal situación.

\section{Bibliografía}

CANUTO, O. The global economy remains unbalanced. Available: www.economonitor.com. Acess: 3 nov. 2016. 
DAS, S. Crash course part 1: the problems of overvalued assets \& high debt. Available: www.economonitor.com. Acess: Sept. 8, 2016.

DAVIES, H. Taking monetary policy to the people. Available: www.projectsyndicate.org. Acess: Oct. 25, 2016.

DERVIS, K. What role for global governance? Available: www.projectsyndicate.org. Acess: Aug. 18, 2016.

EPSTEIN, G. Financialization, rentier interests and central bank policy. In: DEPARTMENT of Economic of Political Economy Research Institute (PERI), University of Massachusetts, Amherst, Ene. 2001.

EPSTEIN, G.; MONTECINO, J. A. Overcharged: the high cost of high finance. New York: Rooselvet Institute. Reimagine The Rules, Jul. 2016.

FASIANOS, A. et al. Financiarización: have we been here before? (WP, n. 869). Available: www.levyinstitute.org. Acess: Jun. 2016.

FELDSTEIN, M. What could go wrong in America? Available: www.projectsyndicate.org. Acess: Oct. 26, 2016.

HAMADA, K. The secret success of adenomics. Available: www.projectsyndicate.org. Acess: Oct. 26, 2016.

HUERTA, A. El ocaso de la globalización. Editado por la Facultad de Economía, Unam, 2017.

ISSING, O. Central banks and the revenge of politics. Available: www.projectsyndicate.org. Acess: Nov. 1, 2016.

KALTENBRUNNER, A. A post keynesian framework of exchange rate determination: a Minskyan approach. JPKE, v. 38, p. 426-448, Dec. 15, 2015.

KOZUL-Wright, R. Returning to investment. Available: www.projectsyndicate.com. Acess: Oct. 6, 2016.

KRUGMAN, P. El blues del mercado alcista. El País. Acess: Jul. 15, 2016.

ORHANGAZI, O. Financial vs real: an overview of the contributions. Role of Finance, en Department of Economic of Political Economy Research Institute (PERI), University of Massachusetts, Amherst, nov. 2011. (WPS, n. 274).

PANIZZA, U. A perfectly crazy idea for the IMF. Available: www.projectsyndicate.org. Acess: Nov. 2, 2016.

REINHART, C. The easy money contagion. Available: www.project-syndicate.org. Acess: Aug. 24, 2016. 
La globalización y la política macroeconómica acentúan la financiarización y la fragilidad...

ROACH, S. S. Desperate central bankers. Available: www.project-syndicate.org. Acess: 26 Sept. 2016.

ROGOFF, K. America's looming debt decisión. Available: www.projectsyndicate.org. Acess: 8 ago. $2016^{\mathrm{a}}$.

ROGOFF, K. Big danger at the lower bound. Available: www.project-syndicate.org. Acess: 2 nov. 2016 b.

STEINBOCK, D. China's Q3 indicates cyclical stabilization, secular challenges. Available: www.economonitor.com. Acess: 27 oct. 2016.

STOCKHAMMER, E. Financialization and the Global Economy. Department of Economic of Political Economy Research Institute (PERI), University of Massachusetts, Amherst, Nov. 2010. (WPS, n. 240).

SUNDARAM, J. K.; POPOV, V. Free trade's diminishing returns. Available: www.project-syndicate.org. Acess: Aug. 5, 2016.

TOPOROWSKI J. The end of finance, 2000 capital market inflation, financial derivatives and pension fund capitalism. Routledge Frontiers of Political Economy Acess: 2000.

TOPOROWSKI, J. European financial policy, as if Banking Mattered. 2014. Mimeo.

TOPOROWSKI, J. Two principles of debt and national income dynamics in a pure credit economy. 2013. Mimeo.

UNCTAD. Las cadenas de valor mundial y el desarrollo: inversión y comercio de valor añadido en la economía Mundial. Ginebra, Feb. 2013.

WRAY, R. Modern money theory: a primer on macroeconomics for sovereign monetary systems. Basingstoke, UK: Palgrave Macmillan, 2012. 